$$
=2
$$

$$
N-\bar{O} 7
$$

NASA Technical Memorandum 106042

\title{
Screening Studies of Advanced Control Concepts for Airbreathing Engines
}

Peter J. Ouzts, Carl F. Lorenzo, and Walter C. Merrill

Lewis Research Center

Cleveland, Ohio

Prepared for the

28th Joint Propulsion Conference and Exhibit cosponsored by AIAA, SAE, ASME, and ASEE

Nashville, Tennessee, July 6-8, 1992

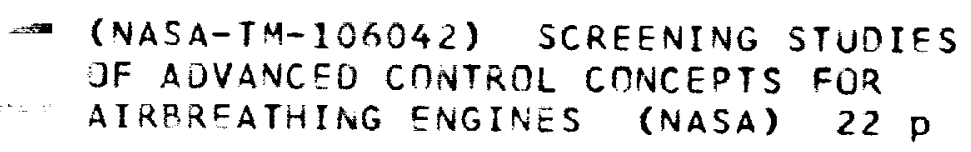

N93-25079 JF AOVANCEO CONTROL CONCEPTS FOR AIRBREATHING ENGINES (NASA) $22 \mathrm{p}$ 


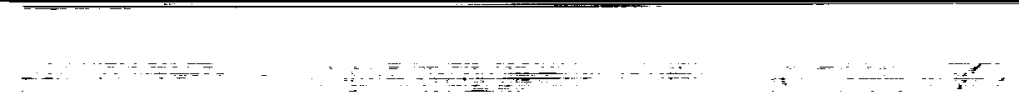

$-:-\ldots+\cdots$

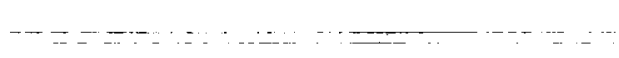

.

$=-. \quad-\ldots+\cdots+\cdots$

(1)- =

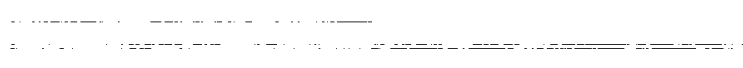

a.

.

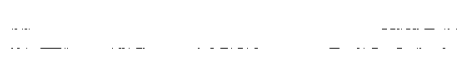

$+\ldots \ldots+\cdots+\cdots+\cdots+\cdots$ 


\title{
SCREENING STUDIES OF ADVANCED CONTROL CONCEPTS FOR AIRBREATHING ENGINES
}

\author{
Peter J. Ouzts, Carl F. Lorenzo, and Walter C. Merrill \\ National Aeronautics and Space Administration \\ Lewis Research Center \\ Cleveland, Ohio 44135
}

\section{SUMMARY}

The application of advanced control concepts to airbreathing engines may yield significant improvements in aircraft/engine performance and operability. Accordingly, the NASA Lewis Research Center has conducted screening studies of advanced control concepts for airbreathing engines to determine their potential impact on turbine engine performance and operability. The purpose of the studies was to identify concepts which offered high potential yet may incur high research and development risk. A target suite of proposed concepts was formulated by NASA and industry. These concepts were evaluated in a two phase study to quantify each concept's impact on desired engine characteristics. To aid in the evaluation three target aircraft/engine combinations were considered: a Military High Performance Fighter mission, a High Speed Civil Transport mission, and a Civil Tiltrotor mission. Each of the advanced control concepts considered in the study are defined and described. The concept potential impact on engine performance was determined. Relevant figures of merit on which to evaluate the concepts are determined. Finally, the concepts are ranked with respect to the target aircraft/engine missions.

\section{INTRODUCTION}

In the sixty years since the introduction of the aircraft gas turbine powerplant tremendous gains in gas turbine performance have been attained. These performance gains have been achieved primarily by gas turbine component designers continually improving component designs. However, as gas turbine technology has matured, performance gains from component design improvements have inexorably slowed and obtaining performance gains has become more difficult. Furthermore, the marginal performance gains of a particular component design change can sometimes be lost in the inherent variations of engine-to-engine manufacture and assembly operations. Therefore, notwithstanding revolutionary technology advances (e.g., higher temperature materials), incremental increases in engine performance via component design improvements will continue to entail ever increasing costs.

Given that engine performance gains via the traditional path of improved component design are becoming more difficult, advanced control systems are being investigated as a cost effective means to attain increased gas turbine performance. Advanced control concepts can provide an additional functionality to the gas turbine system by which increased performance may be obtained. This additional functionality can take many forms. Advanced controls may target better component performance via active control of desired component operating characteristics or better system performance via monitoring and adjustment of individual components to best meet system performance goals. These advanced control concepts hold the potential of relatively large performance gains (relative to those attainable via component design) at little of the cost of component design modifications. While in general the most significant performance gains achieved via advanced control concepts may come from the marriage of component and control design, in some cases advanced control concepts can improve the performance of existing engine designs already in service.

Recognizing the above potential the NASA Lewis Research Center commissioned a study program, the Advanced Control Concepts for Airbreathing Engines program with three major domestic aircraft 
engine manufacturers. The purpose of these studies was to identify, via quantitative determination of engine performance benefits, those advanced control concepts which comprise the high benefit/high risk category in terms of overall aircraft performance. Those control concepts which comprise this highly leveraged group would form the core of continued detailed studies and, if warranted, future development. Therefore, the Advanced Control for Airbreathing Engines studies sought to build the roadmap for future NASA Lewis gas turbine control system research programs.

The Advanced Control for Airbreathing Engines studies were performed by the three industry participants during 1989-1991. This paper summarizes the results of the studies and thereby identifies those control concepts which are best suited for future research and development. The overall scope of the program and how it was conducted is presented first. This is followed by a brief description of an original list of candidate control concepts to be investigated. The preliminary screening of concepts is described along with those concepts selected for further study. Detailed screening studies are reviewed with the significant numerical results highlighted. A final ranking of the control concepts is presented, and finally, a recommendation for further efforts is made by identifying those concepts which are judged to hold the most potential for improving overall engine performance.

\section{PROGRAM DESCRIPTION}

The Advanced Control for Airbreathing Engines studies were structured as a two phase program. The two phase approach was used to provide a hierarchical screening process. Each phase sought to evaluate various control concepts based upon both qualitative and quantitative merits. An initial suite of candidate advanced control concepts was identified by NASA and industry. Using this suite, the first phase of the project was to perform a preliminary screening task whereby a short list of top performers was identified. The preliminary screening process primarily used NASA and industry experience to provide qualitative judgement of which concepts were worthy of future study. It also eliminated from further study concepts which were deemed not viable. Ancillary tasks in the preliminary screening phase were to chose target engine cycles and aircraft missions by which the concepts were evaluated and develop consistent figures of merit such that the individual concepts could be relatively ranked.

Those concepts selected in the preliminary screening phase were then subjected to quantitative analysis to determine their benefits on selected engine performance parameters. The performance merits of each concept were then applied to the target aircraft/engine mission to determine an overall figure of merit. Included in the evaluation process were items such as complexity, risk, etc. Finally, the overall figures of merit were used to rank the concepts. Specific recommendations regarding future research and development based on the study results were made.

\section{PRELIMINARY SCREENING PHASE}

The preliminary screening phase consisted of four tasks:

1) Identify and describe a initial suite of candidate control concepts,

2) Identify and select target aircraft missions with respective engine cycles,

3) Identify and select overall figures of merit by which control concepts would be judged,

4) Performed a qualitative screening process to select concepts for detailed analysis. 
An initial suite of advanced control concepts was formulated by NASA based upon both experience and current literature (Ref. 1). The list was provided to the industry participants who were encouraged to expand the list if they desired. The result was a set of thirteen advanced control concepts for consideration in the preliminary screening phase of the program. A brief description of this initial list of concepts is provided in the Appendix. Note that these concepts comprise a wide spectrum of control system domains from individual component control (e.g., active burner pattern factor control) to overall system control (e.g., performance seeking control). Also note that some concepts have already been the subject of previous research programs (e.g., performance seeking control, Ref. 5,6). However, in the interest of completeness and recognizing that in some cases the concept benefits had yet to be correlated to some of the target aircraft missions selected in this study, these concepts were included in the initial candidate concept list.

The second task of the preliminary screening phase was to select target aircraft missions with respective engine cycles on which the concepts were to be evaluated. Three target aircraft mission profiles were chosen. They were:

1) High Speed Civil Transport (HSCT)

2) Military High Performance Fighter (MHPF)

3) Civil Tiltrotor (CTR)

Representative mission profiles for each of the three missions along with the respective engine cycles are shown in Figs. 1-3. Note that the characteristic elements of each mission tend to reward specific engine performance attributes. For example, the HSCT mission profile is dominated by a long (4246 $\mathrm{nm}$ ), supersonic (Mach 2.4) cruise-climb leg. Therefore, supersonic SFC is a dominant engine performance attribute for this mission. Similarly, the MHPF mission profile with its acceleration and maneuvering elements as well as both subsonic and supersonic cruise legs will reward all aspects of engine performance including operability. Finally, the CTR mission profile with its focus on high-density, intercity passenger commercial operations tends to reward non-traditional (and maybe difficult to quantify) performance attributes such as one-engine inoperative thrust ratings and exhaust emissions.

Along with the selected aircraft mission profiles, the studies attempted to define comprehensive figures of merit so that the sometimes diverse concept benefits could be realistically compared to determine relative advantages. Again, the figures of merit were somewhat dependent upon the particular mission selected. Nominally, take-off gross weight (TOGW) is a good overall figure of merit and was relevant to all three mission profiles. It was selected as the figure of merit for the MHPF mission. However, because commercial viability is such an important driver for the HSCT and CTR missions, direct operation cost (DOC) was chosen as the most relevant figure of merit.

Not all concepts benefits could be realistically distilled to the above FOM's. Concept research and development risk and cost are important aspects to consider but difficult to formulate and translate into a single figure of merit. Likewise, for the CTR mission, engine emissions were proposed to be a significant performance attribute due to the CTR operating in high density markets where government emissions regulations may be in effect by the time this aircraft reaches commercial operation. In these cases, these important performance attributes were noted. 


\section{PRELIMINARY SCREENING RESULTS}

With the initial candidate concepts identified and aircraft missions and figures of merit selected, the goal of the preliminary screening task was to chose a short list of concepts for further study. The basic preliminary screening process was designed to be primarily qualitative and was the choice of the particular industry participant conducting the study. In general, each concept was evaluated by the industry experts on a variety of performance attributes (e.g., specific fuel consumption, operability), and then ranked accordingly. The results of the preliminary screening process, shown in Table 1 , show those concepts which were chosen for further quantitative evaluation for each aircraft mission. Note that some concepts on the initial concept list which appear to have large possible benefits (e.g., active noise suppression for the HSCT mission) were eliminated by industry based upon extremely high risk and unproven technical viability. Other concepts were eliminated from further consideration for a variety of reasons such as the concept perceived payoff to low, difficulty in quantifying the concept benefit given the chosen figures of merit, and the concept not appropriate for a research program. With a short list of candidate concepts identified, the second phase of the study commenced with more detailed quantitative analysis of concept benefits and costs.

\section{DETAILED SCREENING PHASE}

Although each advanced control concept was defined during the preliminary screening phase, the first task of the detailed screening phase was to describe more fully the desired implementation of the selected concepts. Implementation detail is important because some concepts can have different levels of implementation, and therefore different levels of benefit and costs. Identification of concept implementation allowed for realistic comparison of benefits and costs. A brief synopsis of this work is provided below.

\section{Active Burner Pattern Factor Control (BPF)}

The burner pattern factor control concept implementation studied here would actively sense turbine inlet temperature profile and control the profile via individual controlled fuel nozzles. Reduction in burner patter factor could either allow higher average turbine inlet temperatures with no decrease in turbine component life or lower average turbine inlet temperatures with increases in turbine component life.

\section{Combustor Variable Geometry (CVG)}

The combustor variable geometry concept studied here would address design compromises which impact emissions made in fixed geometry combustors. The control mechanism would vary primary and dilution air flows to better control emissions at various engine operating conditions. The implementation would be open-loop as a schedule of engine operating condition.

\section{Compressor Inlet Distortion Control (CIDC)}

Compressor inlet distortion control implementation targeted reducing compressor stability margins by reducing stability threat due to inlet distortion. Two distinct methods were envisioned for reducing the inlet distortion threat via CIDC. The first is a primarily software control mode where an on-board 
control algorithm calculates the level of the inlet distortion stability threat using available aircraft and engine sensed variables. Based upon the calculated level of threat, the operating point of the compression system is set. The higher the threat level, the higher the stability margin; the lower the threat, the lower the stability margin. This is one premise of the Highly Integrated Digital Engine Control (HIDEC) research performed by NASA Dryden Research Facility (Ref. 7). HIDEC studied movement of fan operating line, and therefore fan stability margin, in response to calculated fan distortion levels. This CIDC implementation extends this approach to include distortion effects on the high pressure compressor as well.

The second approach also seeks to identify the inlet distortion level but differs from the above approach in that it will attempt to mitigate distortion effects by active manipulation of the inlet airflow. This approach typically uses selected airflow devices (e.g., sectored inlet guide vanes) to modify the inlet airflow characteristics such that the inlet distortion presented to the compression system is reduced. The net effect is similar to the software approach in that compression stability margins can be reduced with accompanying increases in performance.

\section{Intelligent/Diagnostic Control (IDC)}

Intelligent/diagnostic control as considered in this program was an implementation of a variety of software based control techniques to improve overall engine performance. IDC integrates such advanced control modes as performance seeking control and software based CIDC, and diagnostic systems such as sensor fault detection and isolation. As such, IDC can be thought of as an integration of many separate software based control features. IDC was included in the study with the idea of quantifying total potential impact on engine performance gains from the use of software control modes.

\section{Performance Seeking Control (PSC)}

The basic approach of performance seeking control has been the subject of previous research (Ref. 5,6). The functionality of the PSC approaches considered in this program is similar to the referenced previous research. Accordingly, each industry participant relied on either the published work or their own in-house studies to determine the level of PSC expected benefit. In all cases, PSC was implemented as a software control mode only. Again, the goal of this program was to translate the expected PSC performance gains to the selected aircraft mission figures of merit.

\section{Active Secondary Air Cooling (SAC)}

The active secondary air cooling control studied would modulate cooling airflow to the engine hot components as a function of engine operating condition. Although the control is "active" in that some type of flow modulation device is used, it was envisioned to be an open-loop implementation scheduled with engine operation condition.

\section{Active Stall Control (ASC)}

Similar to CIDC, active stall control seeks to reduce compression system stability margins by ensuring that compression stability can be maintained or generated via active controls. However, ASC addresses the symptom of compressor instability rather that the cause (e.g., inlet distortion). Similar to 
CIDC two approaches for ASC were proffered. The first method, which can be characterized as stall avoidance, seeks only to reduce compressor stability margin by the ability the sense impending stall and in response to this signal, quickly move the system towards a more stable operating point.

The second method will actively ensure compressor stability while operating in what would otherwise be a stall region. More comprehensive than CIDC, ASC would inherently protect compressor stability from all threats including inlet distortion. Considerable research has been performed in active stall control area (Ref. 8) and the implementations offered in this program relied extensively on this pioneering work. However, each industry participant identified their own level of expected compression system performance improvement. This study sought to translate the expected compression performance gains from this type of control into the selected mission figures of merit.

\section{Active Tip Clearance Control (TCC)}

The concept studied here is active control of the turbine tip clearance beyond the existing passive clearance control systems in operation today. Although modulation of cooling air is the means by which clearance is adjusted (similar to existing clearance control systems), the required level of modulation is set by either physically measuring turbine tip clearance via installed sensors or calculating tip clearance via on board control algorithms. The rationale for active control is that tighter clearances, with corresponding greater performance benefits, can be obtained via active control over passive control techniques in use today.

\section{Turbine Variable Geometry (TVG)}

Turbine variable geometry as considered here sought to reduce performance penalties inherent in fixed turbine inlet area designs by matching engine operating condition to the particular aircraft demand. For example, for one engine inoperative conditions, high power is necessary while sacrificing fuel consumption. Considering a one-engine inoperative situation, ability to configure the engine in a high power mode above that achievable with a fixed turbine inlet area would reduce overall engine size requirements for the aircraft. Conversely, for normal cruise operation fuel consumption would be optimized. Therefore, the aircraft cruise performance is not impacted by the high power mode used for one engine inoperative conditions. The net result is smaller engine size with similar overall performance.

The control concept considered in this program would vary turbine inlet area by a variation of turbine inlet vane angle. The actual control would be open-loop, with inlet area scheduled as a function of engine operating conditions.

\section{DETAILED SCREENING ANALYSIS}

The goal of the detailed screening analysis was to quantify performance, benefits, and costs of the selected control concepts on the appropriate aircraft missions. This analysis was performed in three steps:

1) Determination of concept direct benefit and cost,

2) Determination of engine cycle overall performance benefit,

3) Determination of concept figure of merit for target aircraft mission. 
For step 1 direct benefit in this sense means the change in an engine cycle parameter targeted by the particular concept. For example, active stall control concepts directly impacts compressor design stall margin. Therefore, the direct benefit of ASC would be the amount of compressor stall margin reduction achieved by implementation of ASC.

While the engine cycle parameter targeted by a particular concept was well known, the level of impact on that parameter was sometimes not. In most cases, the level of expected benefit was either extracted from previous research studies or estimated by consensus of industry partners and NASA. In those cases where quantification of direct benefits was highly subjective, parameterization was employed to determine the overall trend. Similarly, direct cost usually involved increases in engine weight (e.g., control actuators, sensor hardware). Concept direct benefits and cost were also dependent on the aircraft mission selected.

The second step involved translation of the concept direct benefits and costs into engine cycle performance parameters which were directly applicable to the final figures of merit. The most common of these performance parameters were engine specific fuel consumption (SFC) and engine weight. For this analysis, the industry partners used engine performance computer codes to determine the level of the performance benefits. A concept benefit (e.g., compressor efficiency increases due to reduced stall margin) was implemented in the cycle performance code and the resulting cycle benefit (e.g., SFC) was obtained. The level of sophistication of this computer analysis was dependent on the tools available to the industry participant. For example, in the MHPF analysis, the engine performance computer code could modify the overall engine cycle in response to a concept benefit. For the other missions, this level of sophistication was not present.

Finally, the last step in the quantification process was to use the cycle performance benefits to determine concept effect on the selected figures of merit. Here the approach taken by industry was to determine the sensitivity of various engine cycle performance parameters (e.g., SFC, engine weight) on the desired mission figure of merit. Concept benefits in terms of engine cycle performance were then applied to the sensitivity factors to determine the final figure of merit. Tables $2-4$ summarize the above results for each concept with its respective aircraft mission.

With the concept benefit in terms of the selected figure of merit quantified, the final ranking of the concepts was performed. In addition to the numerical results summarized in the figure of merits, some other issues such as concept technology risk were considered in the final ranking. The final ranking of the concepts is shown on Table 5 .

\section{DISCUSSION OF RESULTS}

The Advanced Control for Airbreathing Engines screening study was designed to provide an overall view of the impact of various advanced control concepts on engine performance and ultimately on the aircraft missions of interest. As such, the studies were conducted to highlight advanced control concepts which show potential for future research and development. Given the limited scope of the program, various assumptions and simplifications were required and justified. Some of these assumptions and simplifications could have significant impact on the quantitative figures of merit. Further, it became evident in the ranking process that given the level of effort in this program, some positive concept performance attributes could not be realistically translated into single quantitative figures of merit. And some concept benefits were highly dependent upon the particular aircraft mission and cycle chosen. Therefore, while the absolute quantitative figure of merit values for the concepts are indeed enlightening, further analysis of expected benefits is probably prudent before absolute confidence can be place on these 
values. Therefore, we have used the final figure of merit values more as a comparative measure between concepts and not as the final judgement for a particular concept. More detailed analysis is indicated for many of the concepts.

Notwithstanding the above, some interesting interpretations of the results can be made. As previously described, the particular aircraft mission selected significantly impacted the final figure of merit for a particular concept. For the MHPF mission, with its emphasis on overall engine performance, all selected concepts had positive benefits. In addition, concepts which effect engine stability (i.e., CIDC, ASC) can have significant potential impact of mission performance in terms of operability, which is not easily translated into the TOGW figure of merit. It should be noted that for the MHPF mission, intelligent engine control was proffered as the integration of other concepts and thereby incorporated individual concepts benefits.

For the HSCT mission specific fuel consumption was the most important element in DOC and concepts which had direct impact on this performance attribute produced the most favorable results. Interestingly, both CIDC and ASC increased direct operating cost for the HSCT mission. This is partly due to the particular HSCT engine cycle studied where reductions in compressor stall margins were not implemented as upward movements of the compressor operating lines, but instead as a lowering of the compressor stall line. For this engine cycle other limits (e.g., compressor exit temperature, exit jet velocity) were violated by an upward compressor operating line movements. Thus, the net effect of both CIDC and ASC reductions in stall margin were reductions in compressor weight at constant efficiency rather than increases in compressor efficiencies which would entail corresponding improvements in specific fuel consumption. The combination of the no effect on specific fuel consumption and the relatively large hardware requirements resulted in increased DOC values for these concepts. Also note that for the HSCT missions, only $3 \%$ reductions in compressor stall margin were envisioned rather than the $5-10 \%$ reductions allowed for the other missions. The results for CIDC and ASC could be different (i.e., a reduction in DOC) given a different HSCT engine cycle definition which would allow higher compressor operating lines and larger stall margin reductions. Finally, active secondary air cooling control was not useful for the particular HSCT engine cycle because maximum cooling air flows were required in the cruise operating condition versus typical cooling flow maximums at the takeoff condition. Therefore, given the short duration of the takeoff condition, little gain could be expected from any modulation of cooling air flow.

The CTR results were mixed with four of the six considered concepts actually increasing DOC. However, the CTR mission analysis highlighted both the limited resources of this study and the difficulties in translating diverse concept benefits into a single figure of merit. For example, burner pattern factor control provided an estimated doubling of turbine hot component life, however due to the level of analysis undertaken this benefit could not be directly included in the final figure of merit. Likewise, implementation of combustor variable geometry decreased engine emissions which could be very important if emissions regulations are implemented in the high-density markets a CTR would serve. Again, this benefit could not directly be translated into DOC. Therefore, the CTR mission highlighted the fact that more detailed analysis is indicated on several of these concepts to better determine their potential impact.

Another overall interpretation of the results is to group the concepts into two categories: 1) Component control concepts (BPF, CVG, CIDC, SAC, ASC, TCC, TVG) where the concept targets a particular engine component (e.g., burner pattern factor affecting turbine inlet temperature), and 2) System control concepts (e.g., IDC, PSC) where the concept operates on the overall engine system. For the first group, the results of the screening studies were mixed. This is in part due to component designers having squeezed their component designs to achieve maximum efficiency to the level that only revolutionary advances in component operation aided by advanced controls (e.g., ASC) seem to hold 
significant performance gains. Many times these concepts involve engine weight increases due to control hardware and the potential performance gains are only realized via component redesign. Conversely, the system type concepts are mostly software based (and therefore do not impact engine weight) and promise significant performance gains without incurring major (or any) hardware modification/redesign. In fact, both the software based control concepts promised the most potential performance gains of all the concepts studied. The above scenario was evident in the concept rankings where the system concepts (which did not incur weight/development costs) fared better than the component concepts (which did incur weight/development costs) in the final figures of merit.

As previously noted, other important aspects such as concept complexity, development risk, and estimated life cycle cost were considered in the detailed screening phase. Although in most cases these aspects were difficult to incorporate into the mission figures of merit, these aspects were studied and provide additional valuable information on the relative merits of each concept. The reader is referred to the final industry reports on the program (Ref. 2-4) for more information on these results.

\section{CONCLUSIONS}

Screening studies were performed on a selected set of advanced control concepts for airbreathing engines. The screening studies highlighted the performance benefits and costs of the selected concepts on three relevant aircraft missions. Overall, the studies show that software logic control modes such as Performance Seeking Control and Intelligent/Diagnostic Control have the best potential impact on aircraft and engine performance. Component type control concepts such as Active Stall Control and Burner Pattern Factor hold promise, but more detailed studies are necessary to better determine their overall impact

\section{ACKNOWLEDGMENT}

The authors wish to express their gratitude to Art Glassman of the NASA Lewis Aeropropulsion Analysis Office for his input and guidance in this program. 


\section{APPENDIX}

The following is a brief description of the initial set of advanced control concepts considered in the preliminary screening phase of the project. The descriptor "active", in most cases, denotes a higher level of control functionality than currently in use today (i.e., actively controlling tip clearance via sensing and actuating systems rather than the use of simple cooling passages).

\section{Active Burner Pattern Factor Control (BPF)}

Increase turbine inlet average temperatures with no impact on turbine life by actively controlling burner pattern factor to eliminate hot streaks.

\section{Active Afterburner Rumble Suppression (ARS)}

Sense and suppress afterburner combustion pressure oscillations to reduce noise and after burner liner weight, and increase afterburner life.

\section{Active Combustor Howl/Growl Suppression (CHGS)}

Sense and suppress combustor pressure oscillations to reduce noise and increase combustor life.

$$
\text { Combustor Variable Geometry (CVG) }
$$

Control combustor fuel/air ratio characteristics by modulation of primary and dilution air flows to achieve desired emission levels.

\section{Compressor Inlet Distortion Control (CIDC)}

Reduce necessary compressor stability margins by sensing and/or mitigating distorted inlet air flows.

\section{Active Fuel Nozzle Staging (FNS)}

Improve engine start characteristics by staging fuel nozzles during start procedure.

$$
\text { Intelligent/Diagnostic Control (IDC) }
$$

Use a variety of software based "intelligent" control modes such as performance seeking control, diagnostic systems, and sensor failure and isolation to enhance overall engine performance. 


\section{Active Jet Noise Suppression (JNS)}

Sense and suppress near field pressure oscillations in jet exhaust to reduce jet emission noise.

$$
\text { Performance Seeking Control (PSC) }
$$

Enhance engine performance via on-line engine performance monitoring and optimization.

$$
\text { Active Secondary Cooling Airflow (SAC) }
$$

Actively modulate cooling flows to turbine hot parts to take of advantage of reduced cooling air requirements for off-design operating conditions.

\section{Active Stall Control (ASC)}

Actively control compression system stability to either reduce necessary compressor stability design margins and/or operate compression systems in a nominally stalled region.

\section{Active Tip Clearance Control (TCC)}

Sense or calculate turbine tip clearance and actively modulate cooling air flows to control clearance.

$$
\text { Turbine Variable Geometry (TVG) }
$$

Modulate turbine inlet area to match desired engine operating conditions. 


\section{REFERENCES}

1. Epstein, A.H.: "Smart" Engine Components. A Micro in Energy Blade? Aerosp. Am., vol. 24, Jan. 1986, pp. 60-64.

2. Ralph, R.A.: Advanced Control for Airbreathing Engines. Final Report. NASA CR-189203, 1992.

3. Bansal, I.: Advanced Control for Airbreathing Engines. Final Report. NASA CR-189204, 1992.

4. Bough, R.M.: Advanced Control for Airbreathing Engines. Final Report. NASA CR-189205, 1992.

5. Berg, D.F., et al.: Performance Seeking Control. Report AFWAL-TR-88-2067-VOL-1, 1989.

6. Lambert, H.H., et al.: Preliminary Flight Evaluation of an Engine Performance Optimization Algorithm. AIAA Paper 91-1998, 1991.

7. Highly Integrated Digital Electronic Control Symposium. NASA CP-3024, 1989.

8. Greitzer, E.M., et al.: Dynamic Control of Aerodynamic Instabilities in Gas Turbine Engines. Steady and Transient Performance Predictrion of Gas Turbine Engines, AGARD-LS-183, AGARD, 1992, $20 \mathrm{p}$. 


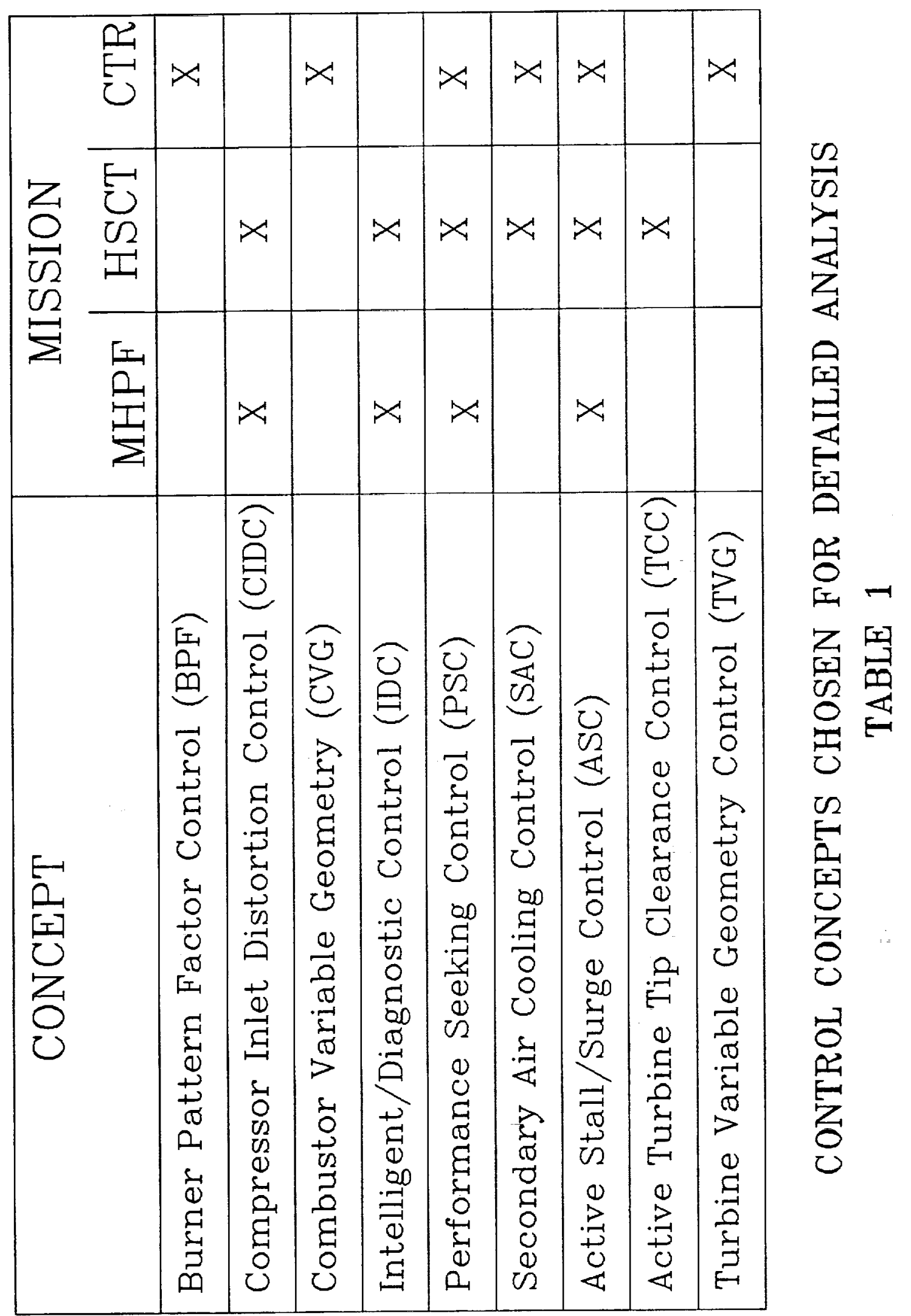




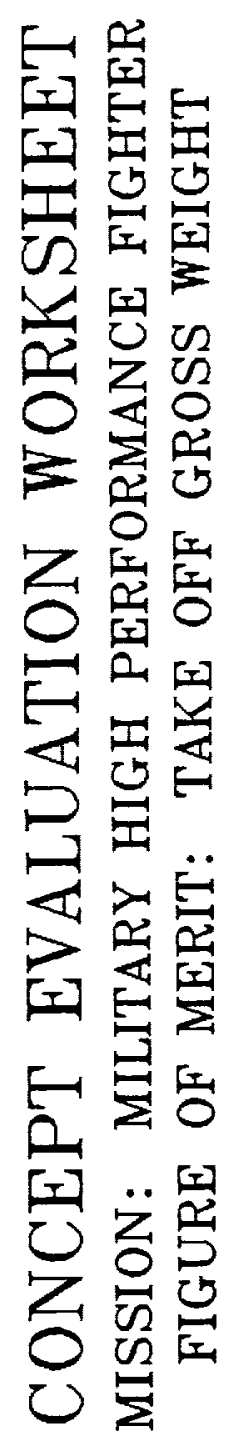

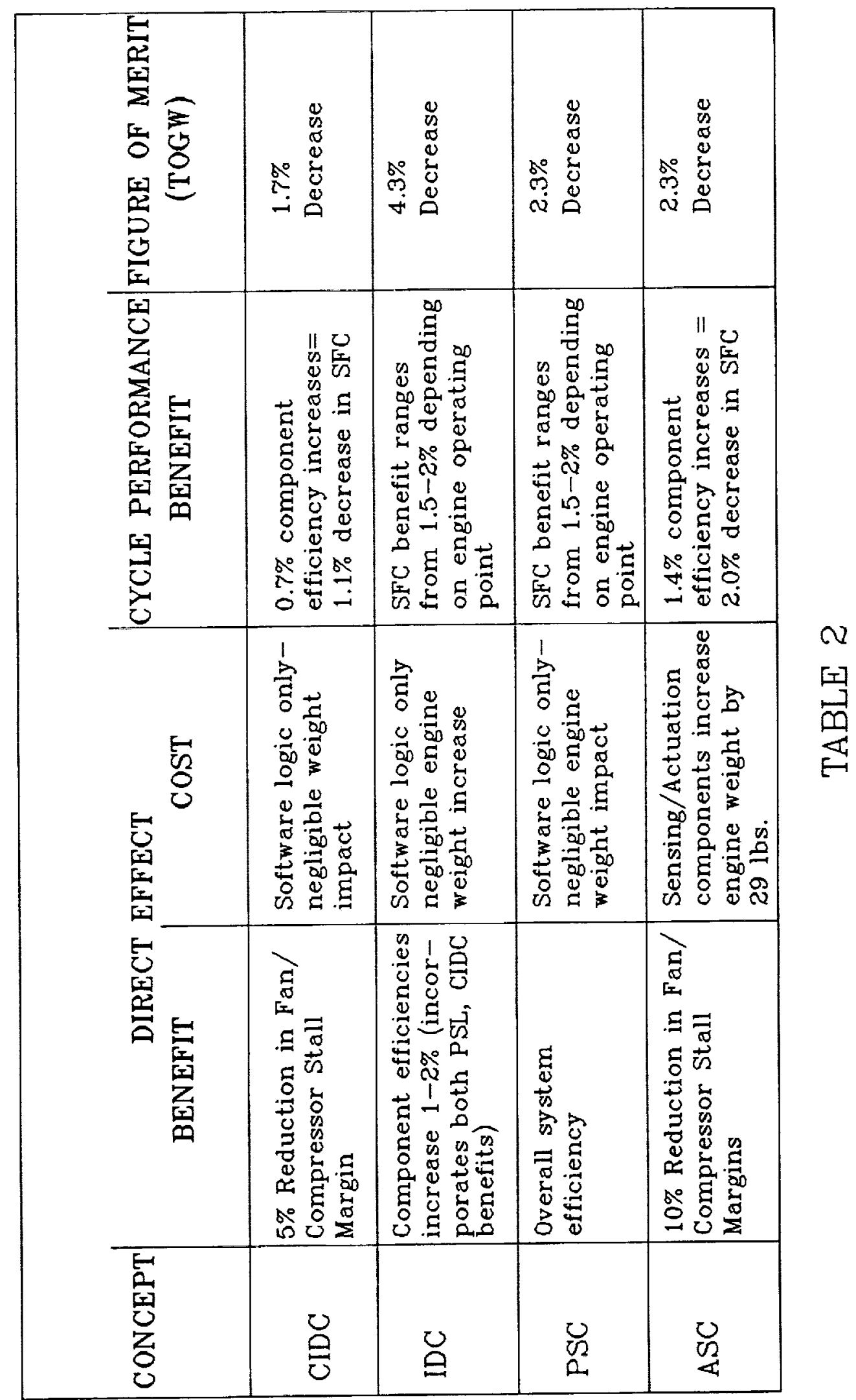




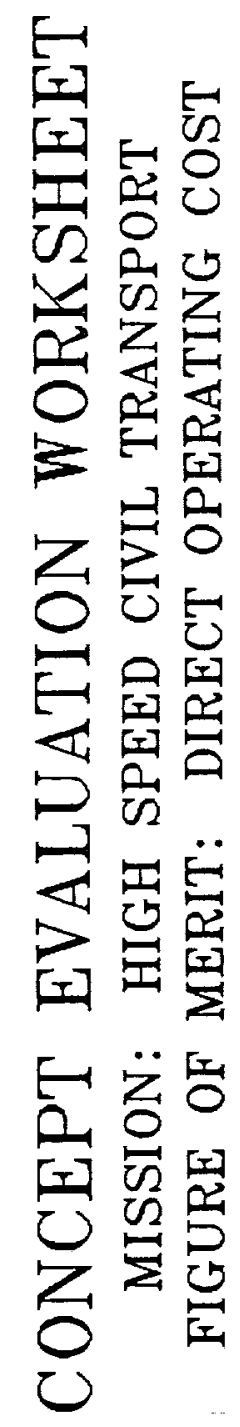

\begin{tabular}{|c|c|c|c|c|c|}
\hline 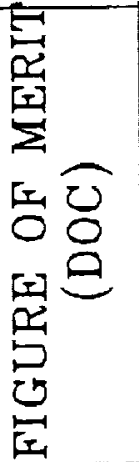 & 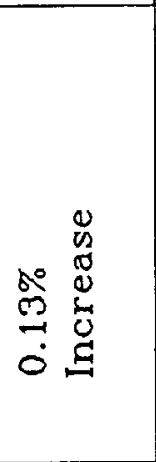 & 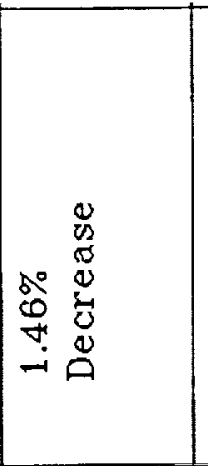 & 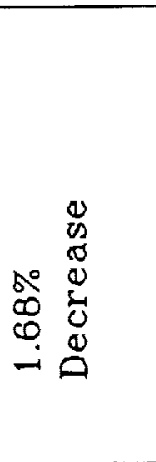 & 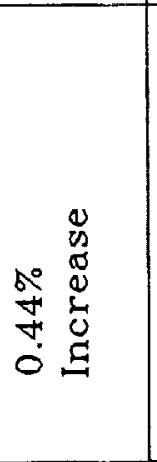 & 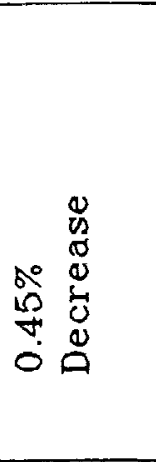 \\
\hline 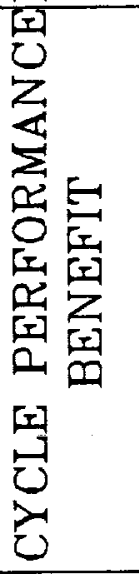 & 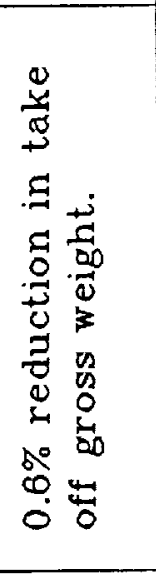 & 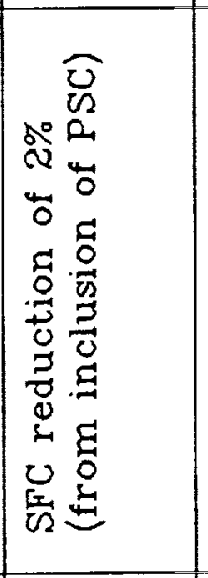 & 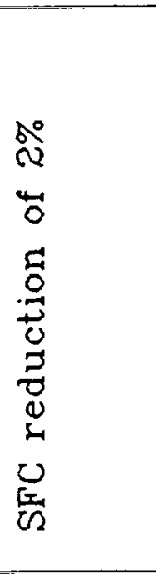 & 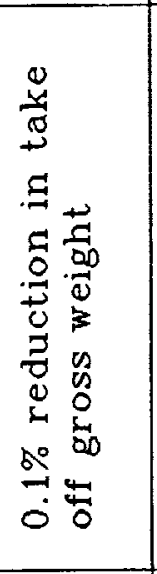 & 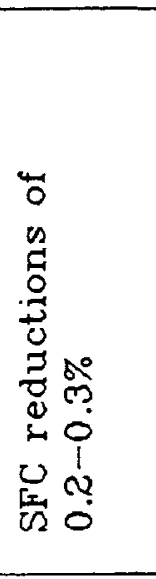 \\
\hline 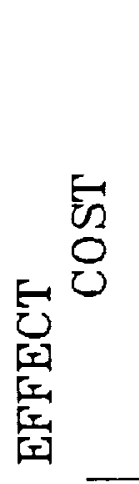 & 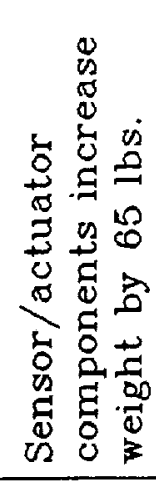 & 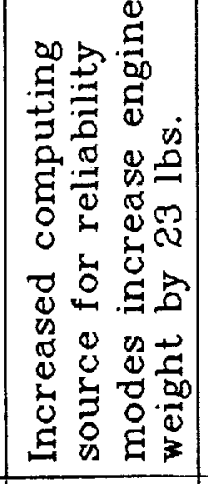 & 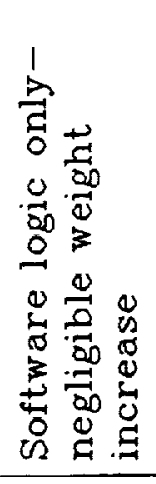 & 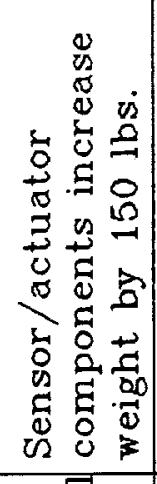 & 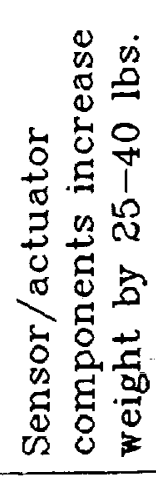 \\
\hline 舅罟 & 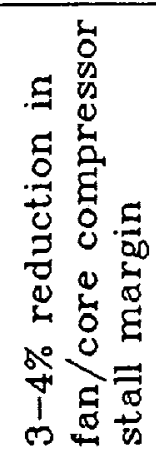 & 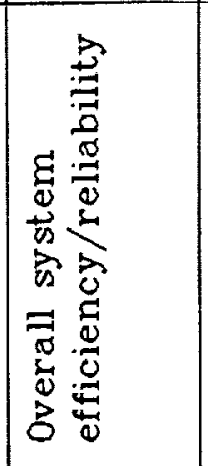 & 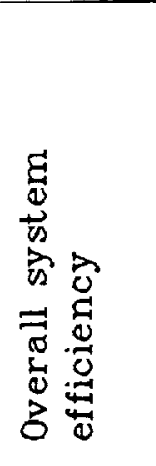 & 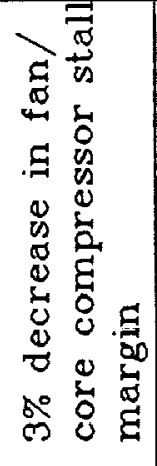 & 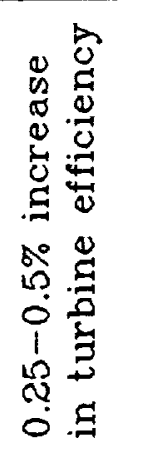 \\
\hline 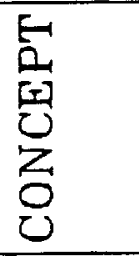 & 号 & 昌 & $\begin{array}{l}\text { Un } \\
a\end{array}$ & 足 & U \\
\hline
\end{tabular}

焉 


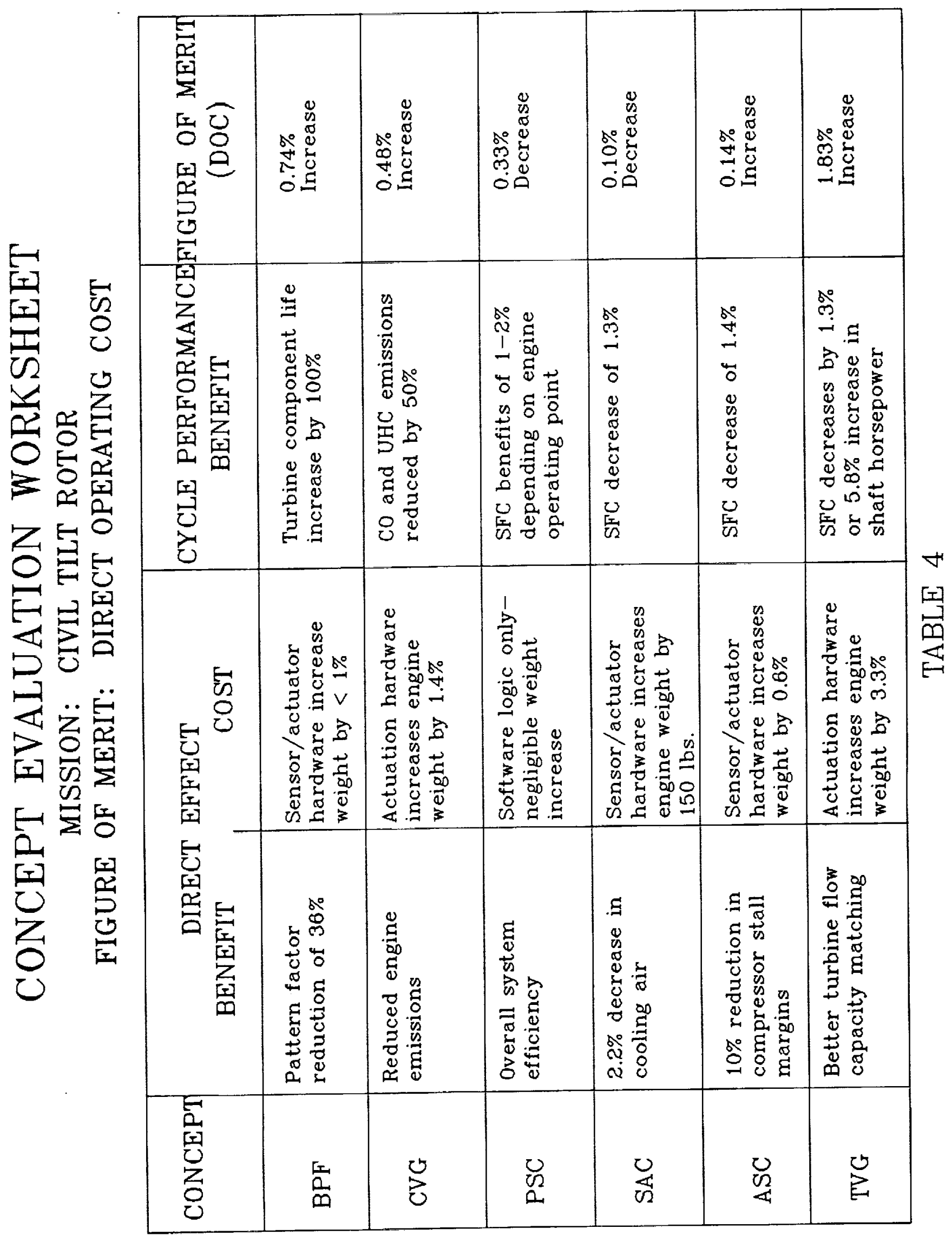




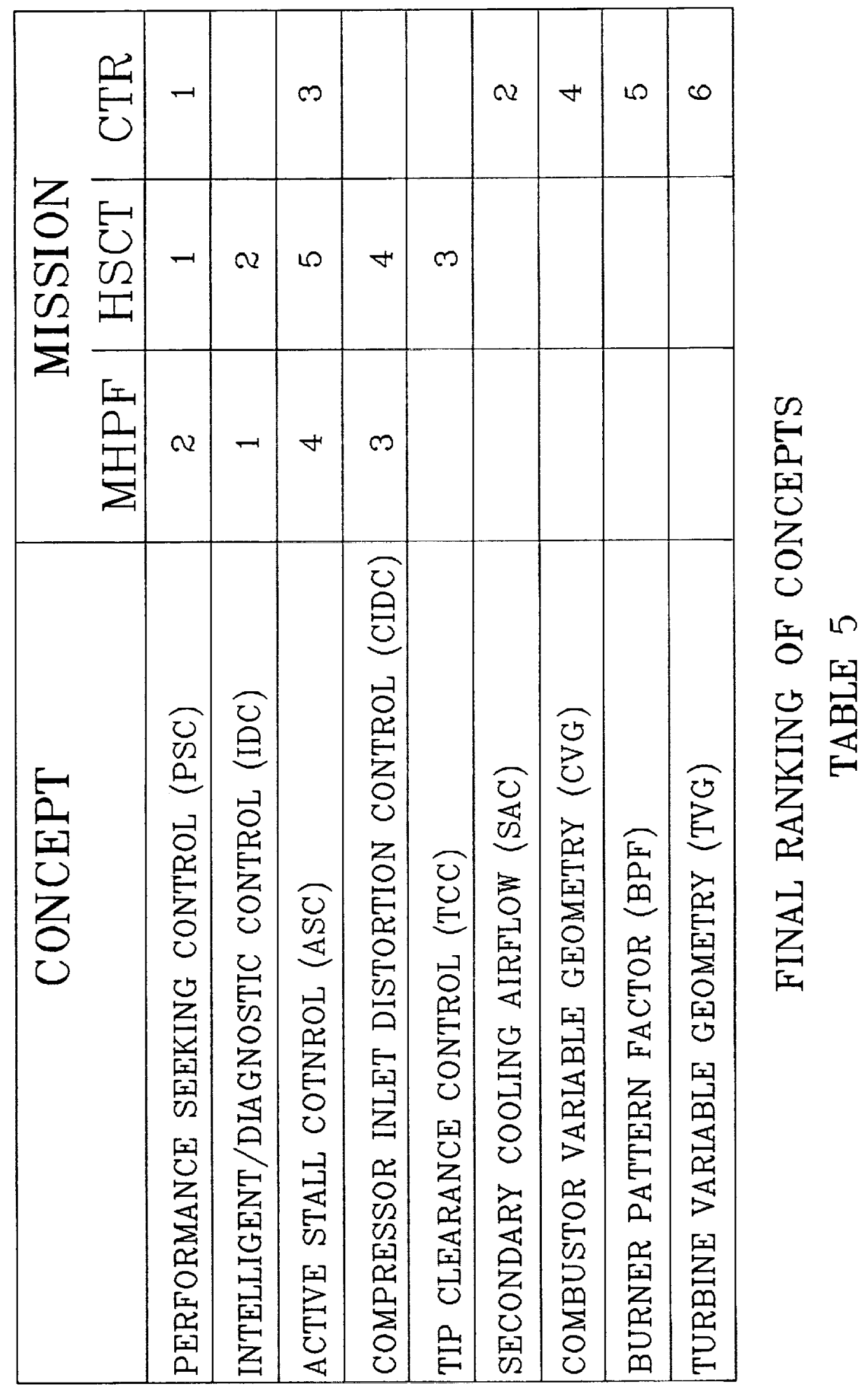




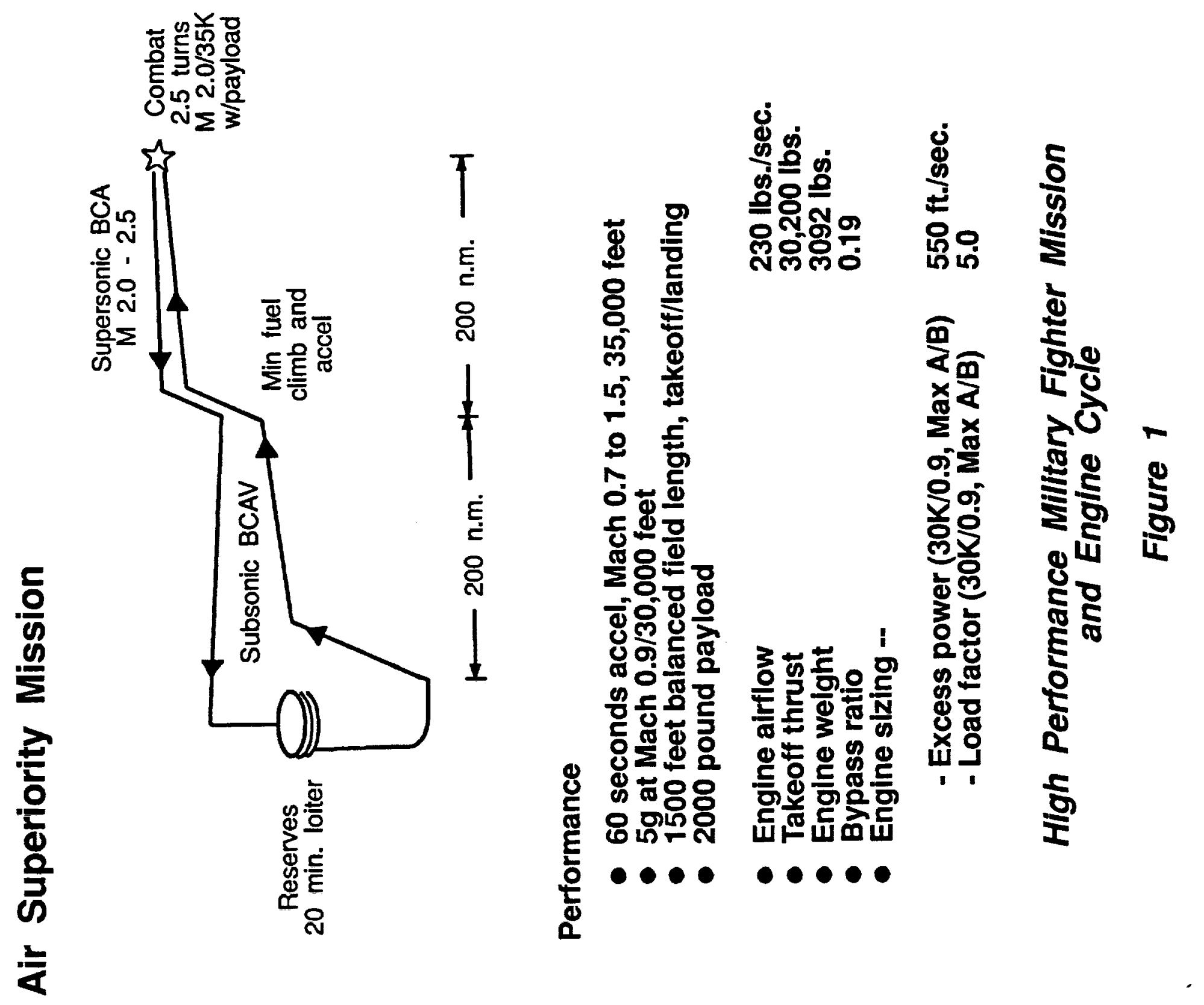



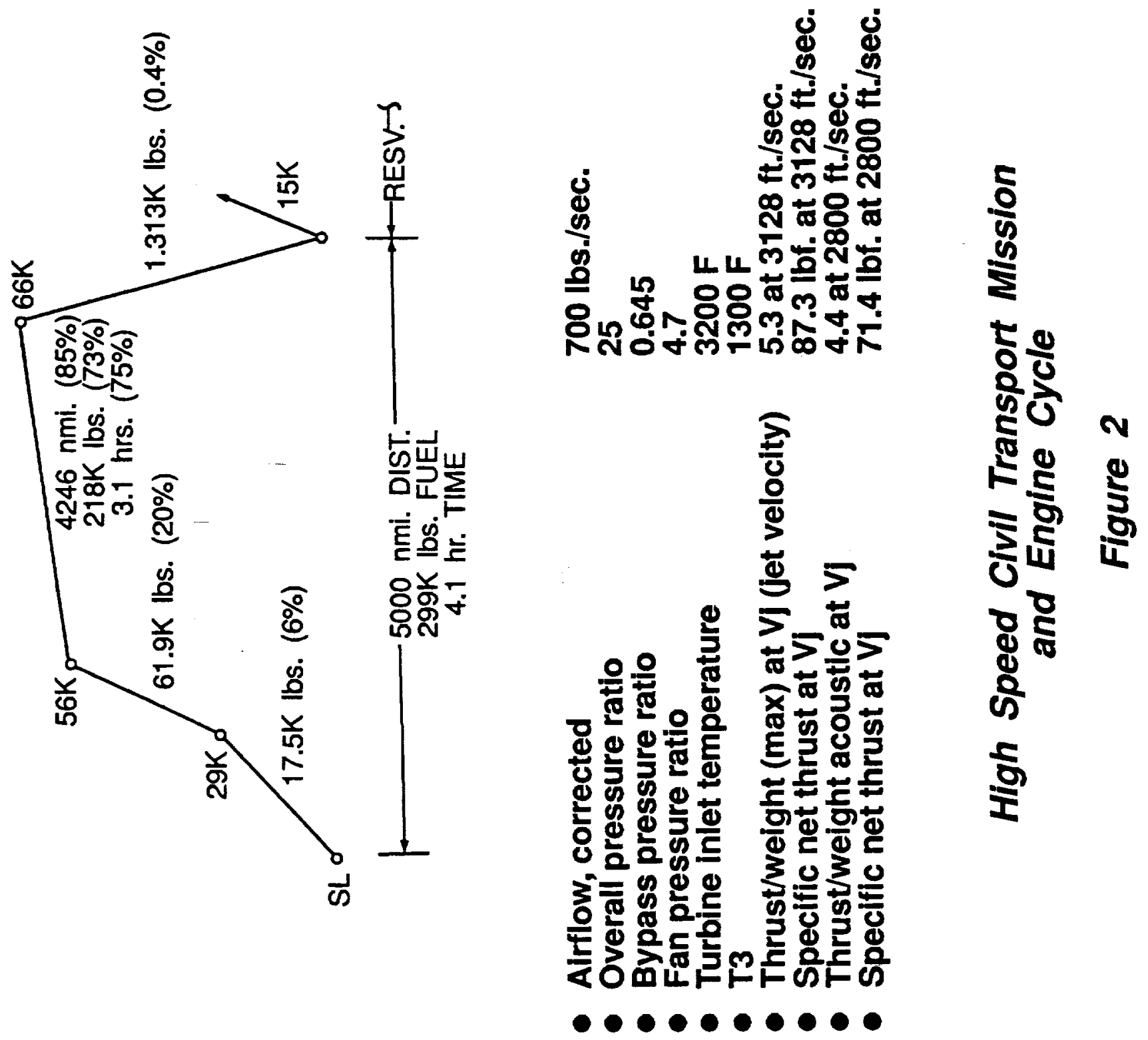

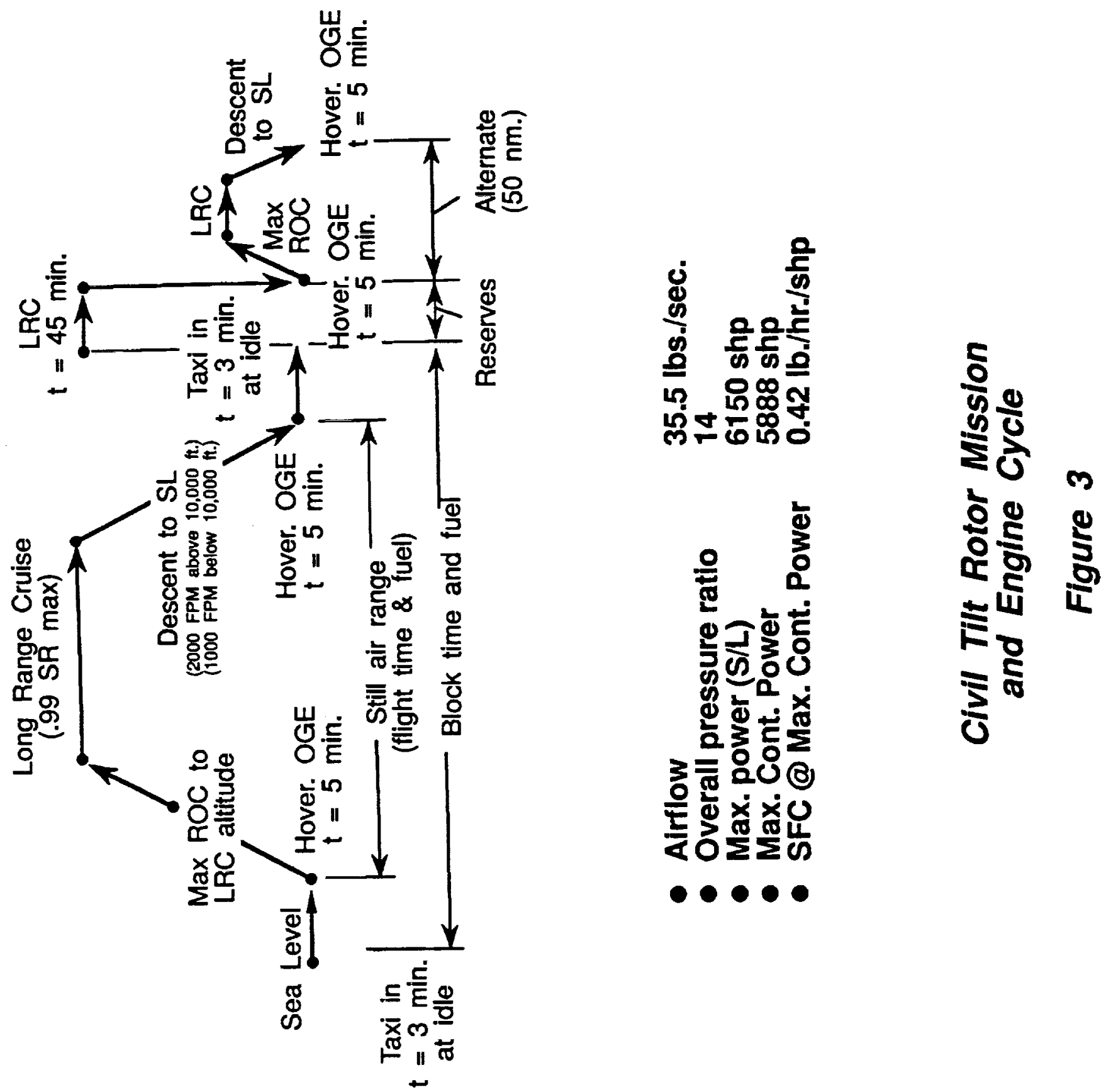

Public reporting burden for this collection of information is estimated to average 1 hour per response, including the time for reviewing instructions, searching existing data sources,

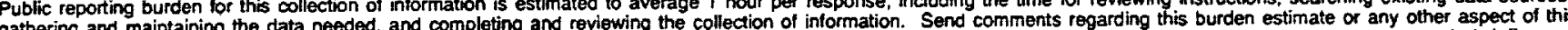
gathering and maintaing Davis Highway, Suite 1204, Artington. VA 22202-4302, and to the Office of Management and Budget, Paperwork Reduction Project (0704-0188), Washington, DC 20503.

\begin{tabular}{|l|l|l|}
\hline 1. AGENCY USE ONLY (Leave blank) & $\begin{array}{c}\text { 2. REPORT DATE } \\
\text { March } 1993\end{array}$ & $\begin{array}{r}\text { 3. REPORT TYPE AND DATES COVERED } \\
\text { Technical Memorandum }\end{array}$ \\
\hline
\end{tabular}

4. TITLE AND SUBTITLE

Screening Studies of Advanced Control Concepts for Airbreathing Engines

6. AUTHOR(S)

Peter J. Ouzts, Carl F. Lorenzo, and Walter C. Merrill

\section{PERFORMING ORGANIZATION NAME(S) AND ADDRESS(ES)}

National Aeronautics and Space Administration

Lewis Research Center

Cleveland, Ohio 44135-3191

9. SPONSORING/MONITORING AGENCY NAMES(S) AND ADDRESS(ES)

National Aeronautics and Space Administration

Washington, D.C. 20546-0001
E-7620

\section{SUPPLEMENTARY NOTES}

Prepared for the 28th Joint Propulsion Conference and Exhibit cosponsored by AIAA, SAE, ASME, and ASEE, Nashville, Tennessee, July 6-8, 1992. Responsible person, Peter J. Ouzts, (216) 433-6469.

128. DISTRIBUTION/AVALABILTY STATEMENT

Unclassified - Unlimited

Subject Category

\section{ABSTRACT (MaxImum 200 words)}

The application of advanced control concepts to airbreathing engines may yield significant improvements in aircraft/ engine performance and operability. Accordingly, the NASA Lewis Research Center has conducted screening studies of advanced control concepts for airbreathing engines to determine their potential impact on turbine engine performance and operability. The purpose of the studies was to identify concepts which offered high potential yet may incur high research and development risk. A target suite of proposed concepts was formulated by NASA and industry. These concepts were evaluated in a two phase study to quantify each concept's impact on desired engine characteristics. To aid in the evaluation three target aircraft/engine combinations were considered: a Military High Performance Fighter mission, a High Speed Civil Transport mission, and a Civil Tiltrotor mission. Each of the advanced control concepts considered in the study are defined and described. The concept potential impact on engine performance was determined. Relevant figures of merit on which to evaluate the concepts are determined. Finally, the concepts are ranked with respect to the target aircraft/engine missions.

\begin{tabular}{|c|c|}
\hline \multicolumn{2}{|c|}{$\begin{array}{l}\text { 14. SUBJECT TERMS } \\
\text { Control; Airbreathing engine }\end{array}$} \\
\hline $\begin{array}{l}\text { 17. SECURTYY CLASSIFICATION } \\
\text { OF REPORT } \\
\text { Unclassified }\end{array}$ & $\begin{array}{l}\text { 18. SECURITY CLASSIFICATION } \\
\text { OF THIS PAGE } \\
\text { Unclassified }\end{array}$ \\
\hline
\end{tabular}

19. SECURITY CLASSIFICATION OF ABSTRACT Unclassified

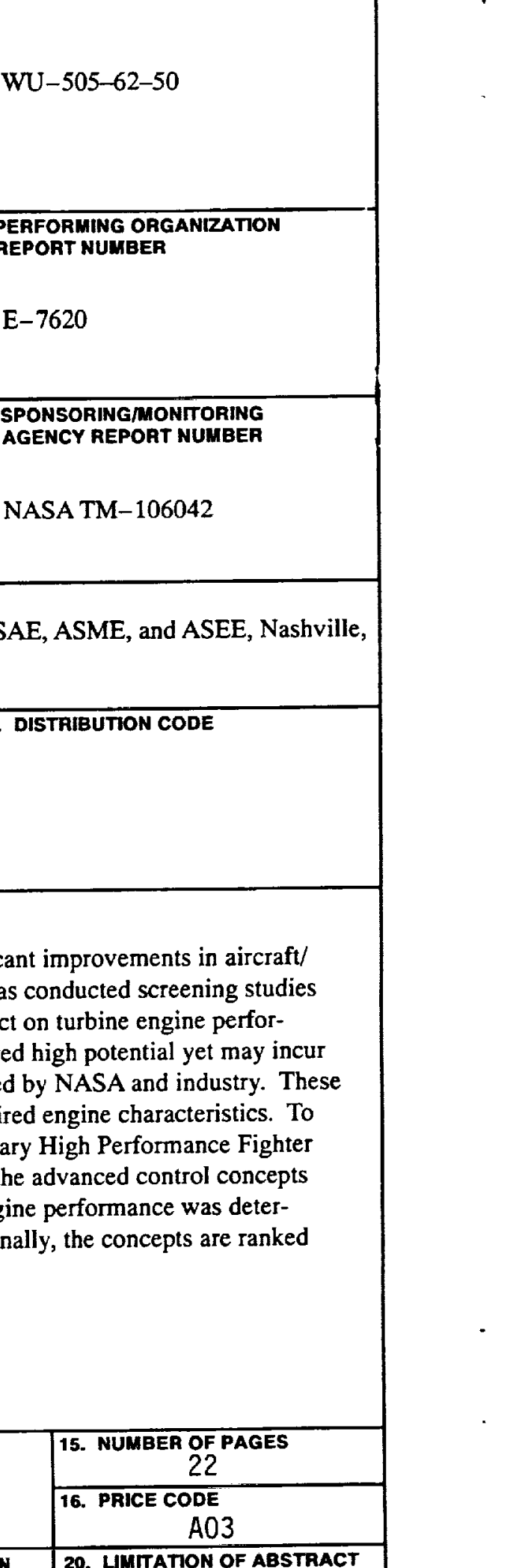

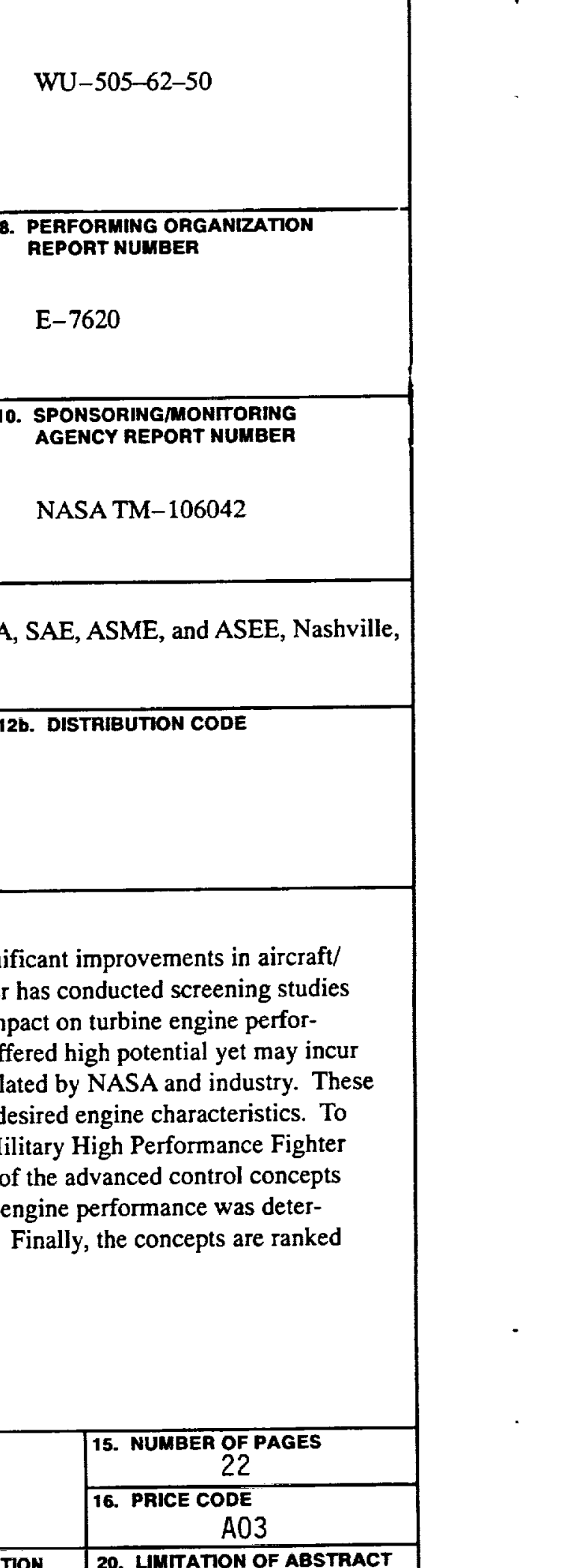

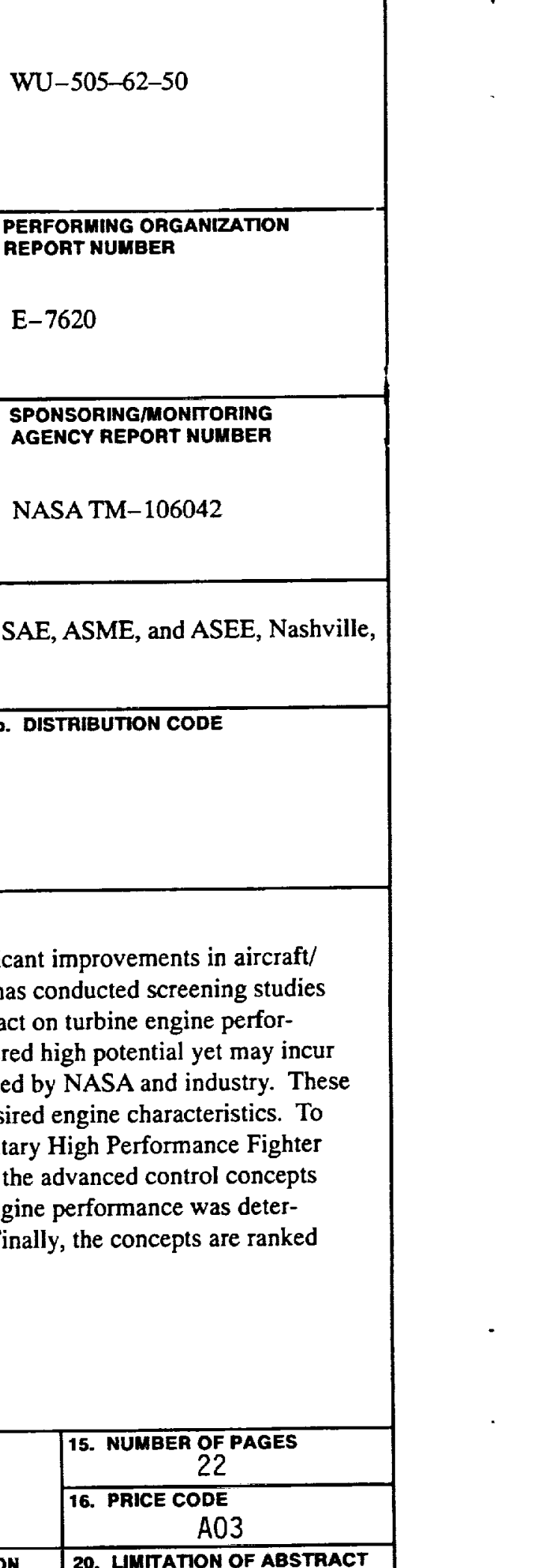

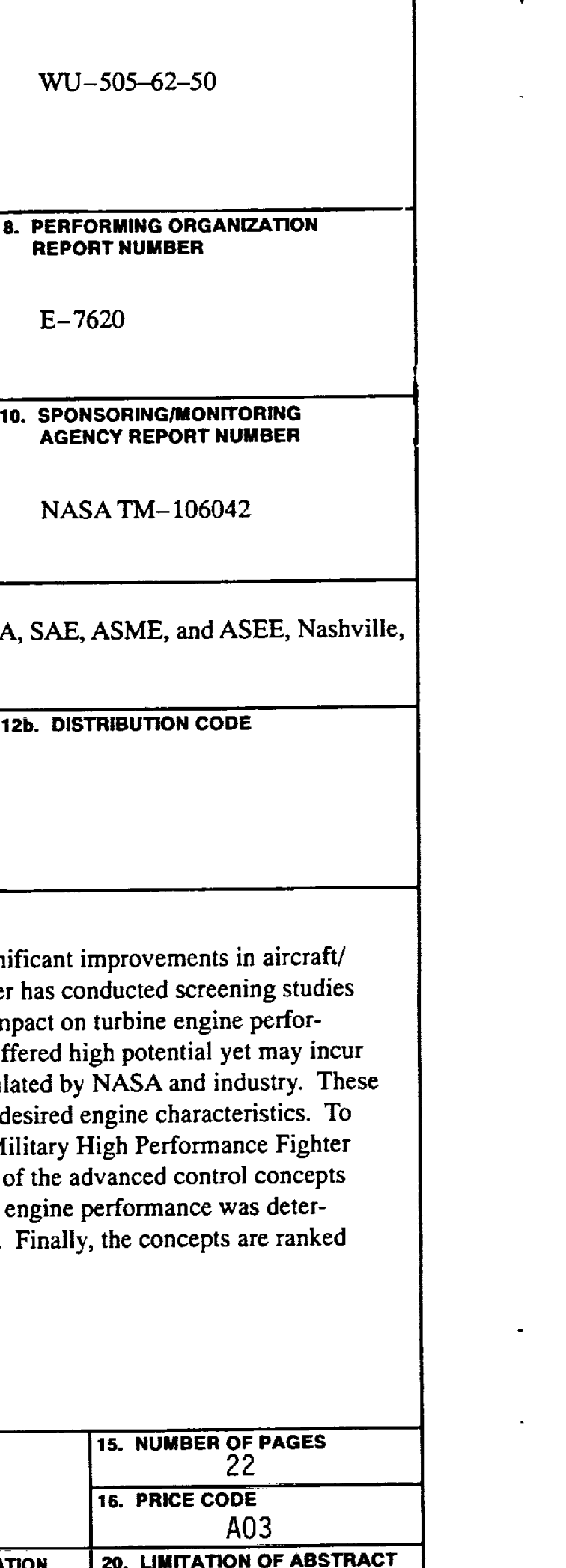

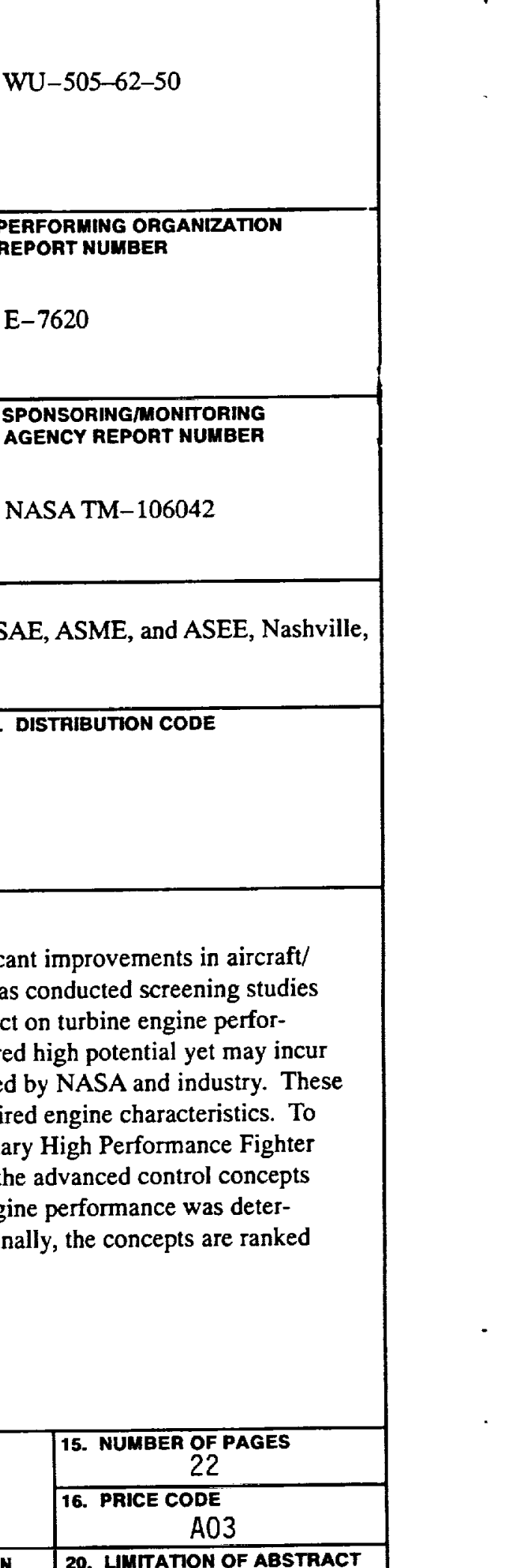

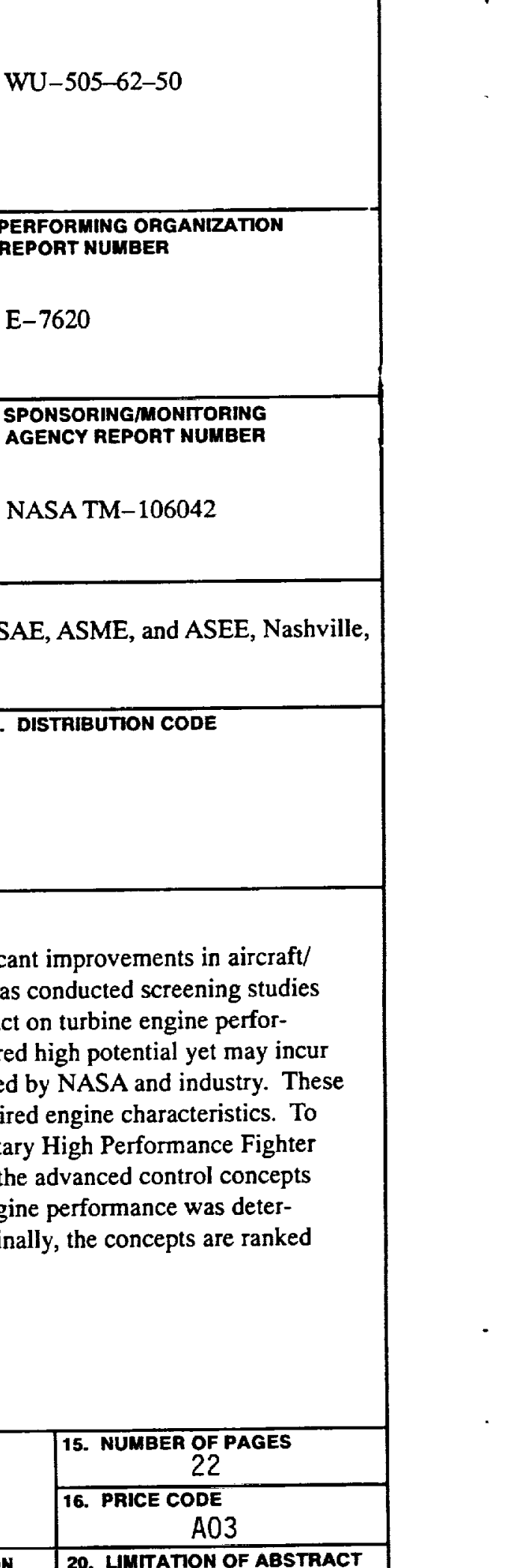

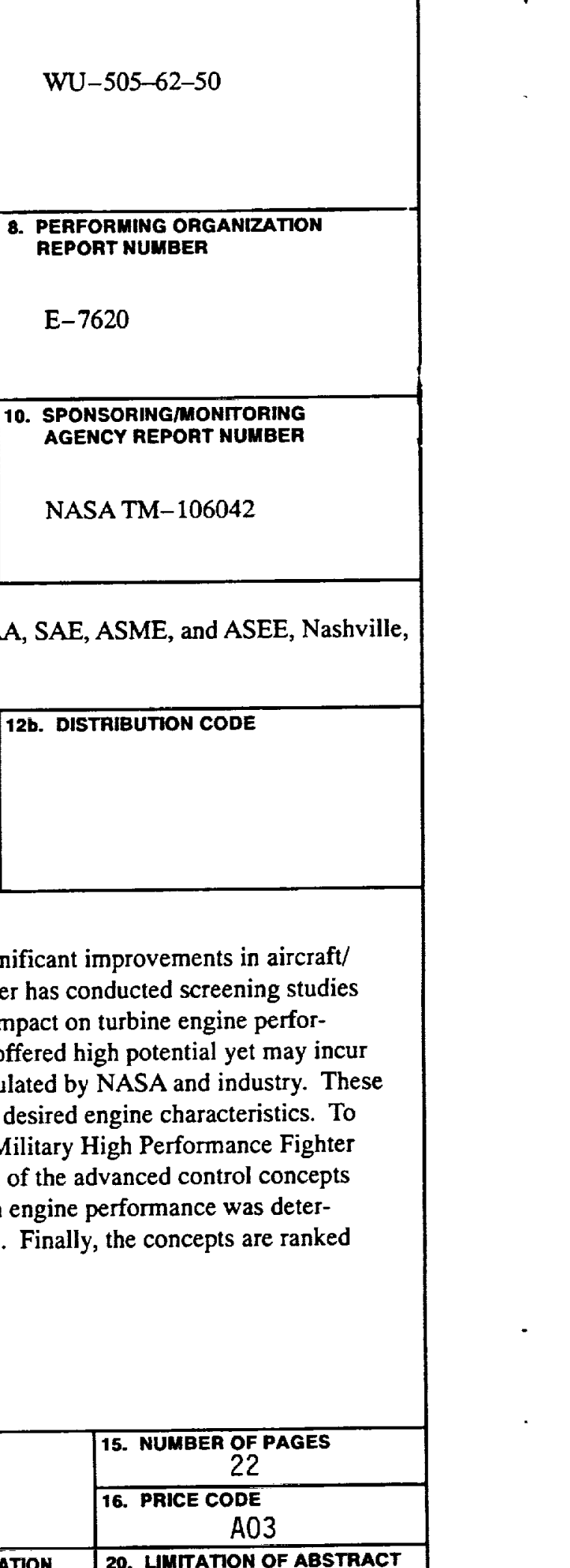

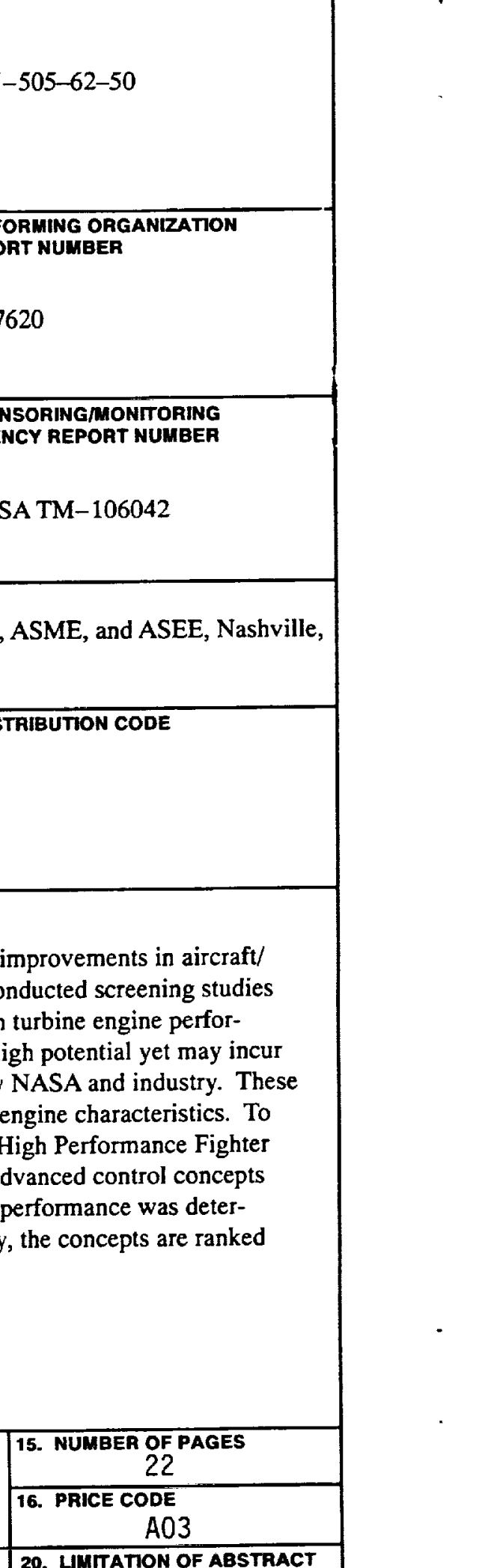

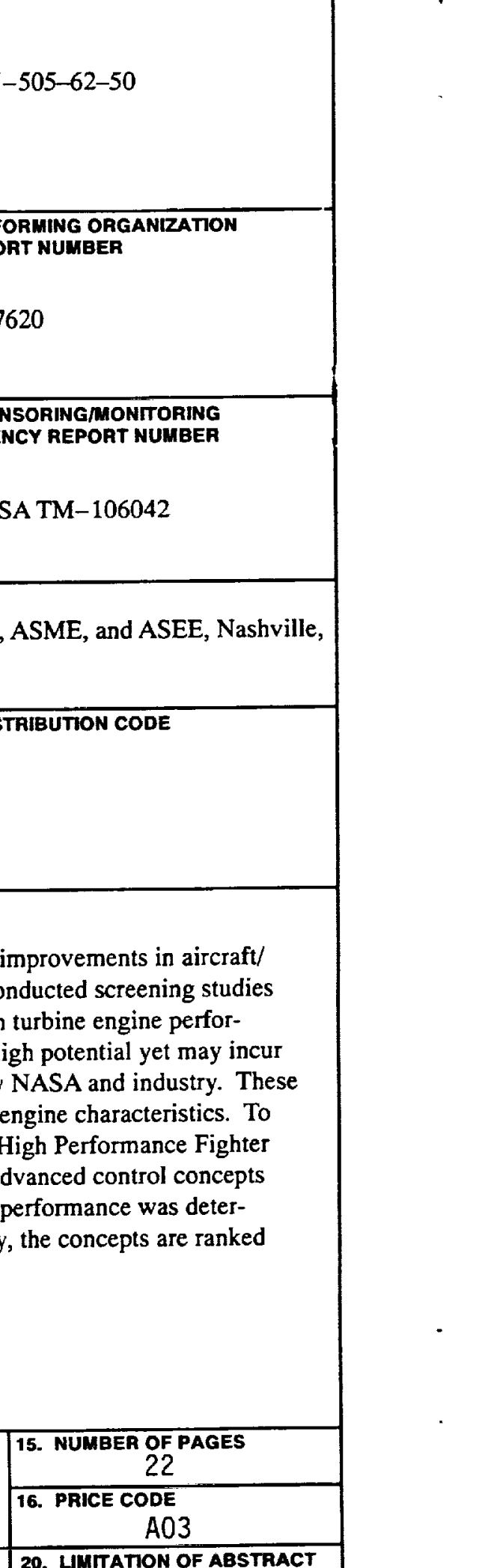

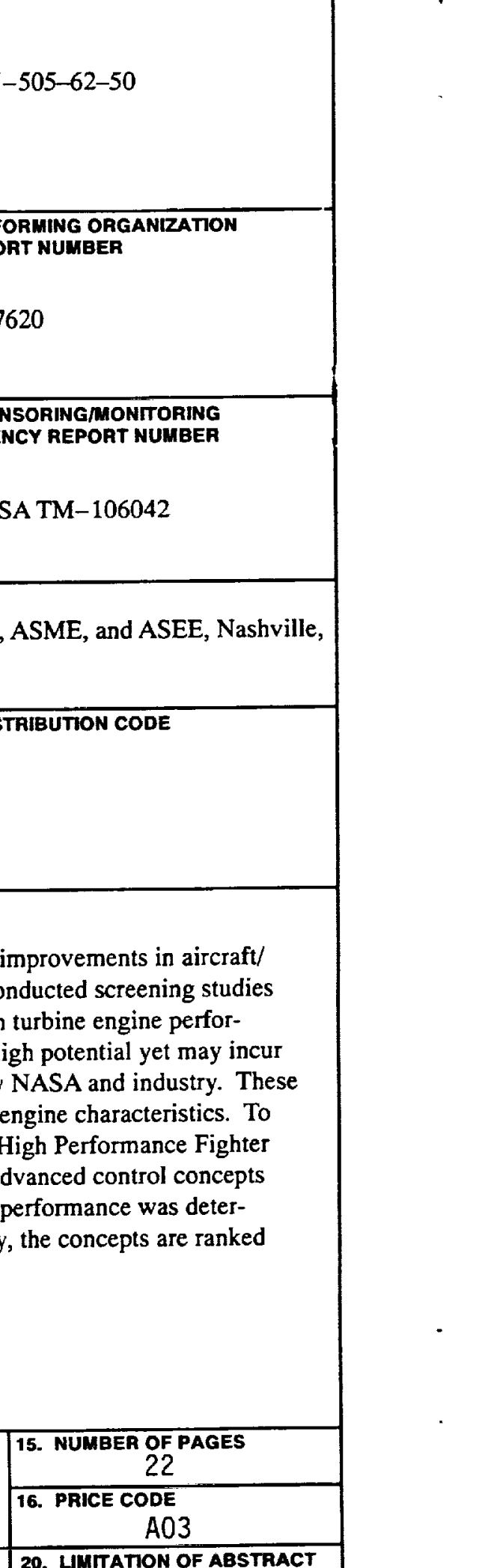

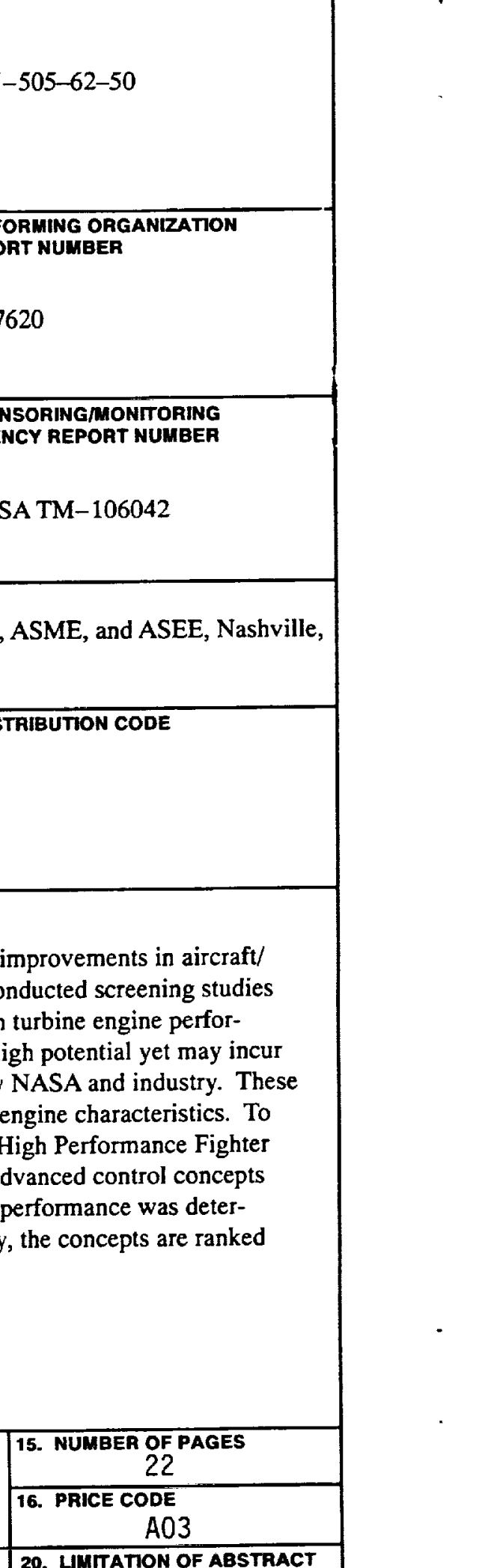
20. LMMTATION OF ABSTRACT 